\title{
Extramedullary Plasmacytoma of the Nasal Cavity: Case Report
}

\author{
Lezrag $\mathrm{M}^{*}$, El Bousaadani $\mathrm{A}^{1}$, Allouane $\mathrm{M}^{2}$, Abada $\mathrm{R}^{1}$, Rouadi $\mathrm{S}^{1}$, Roubal $\mathrm{M}^{1}$ and Mahtar $\mathrm{M}^{1}$ \\ ${ }^{1}$ Department of ENT, “20 August” Hospital, Ibn Rochd University Hospital, Casablanca, Morocco \\ ${ }^{2}$ Faculty of Medicine and Pharmacy, Casablanca, Morocco
}

${ }^{*}$ Corresponding author: Lezrag M, Department of ENT Service and Neck, Surgery, Ibn Rushd Chu, Casablanca, Morocco, Tel: 002126628324 83, E-mail: amic2011@gmail.com

Citation: Lezrag M, El Bousaadani A, Allouane M, Abada R, Rouadi S, et al. (2016) Extramedullary Plasmacytoma of the Nasal Cavity: Case Report. J Case Rep Stud 4(3): 303. doi: 10.157444/2348-9820.4.303

Received Date: December 24, 2015 Accepted Date: June 17, 2016 Published Date: June 20, 2016

\begin{abstract}
The extramedullary plasmacytoma is a rare malignant proliferation clone secreting a monoclonal immunoglobulin. The location to the upper aerodigestive tract represents $80-90 \%$ of cases. We report a extramedullary plasmacytoma nasopharyngeal location in a 39 year old patient. She consulted for nasal obstruction and recurrent epistaxis. The endoscopic exploration and CT scan of the nasal cavities revealed a tumor process of the posterior superior wall of nasopharynx. Histological study of biopsy confirmed the location of a nasopharyngeal plasmacytoma to light chains Kappa with amyloid deposits. A comprehensive review of possible multiple myeloma was negative and finding an isolated extramedullary plasmacytoma. The patient received chemotherapy and radiotherapy with favorable evolution.
\end{abstract}

Keywords: Extramedullary plasmacytoma; Nasal cavity; Chemotherapy; Radiotherapy

\section{Introduction}

The extramedullary plasmacytoma is a rare malignant proliferation clone secreting a 31 monoclonal immunoglobulin. It has the same histological and immunological properties as 32 multiple myelomas, but differs by the absence of medullary invasion, the occurrence within 33 soft tissue and localized nature, single or more rarely multiple of proliferation. The location to 34 the upper aerodigestive tract represents $80-90 \%$ of cases [1,2].

\section{Case report}

A 39-year-old presented to our ENT and Head and neck service with a 1-year history of a nasal obstruction and recurrent epistaxis. She had an unremarkable medical history. On hysical examination, we found an arch of the hard palate covered with a normal appearance mucosa. Endoscopy of the nasal cavities and computed tomography (CT) scan of the face revealed a tumor process of the posterior superior wall of nasopharynx with no signs of erosion of the maxillary floor.

The biopsy under local anesthesia mass concluded with monoclonal plasma cell proliferation evoking a plasmacytoma. Cavaire type mucosa including the lamina propria is occupied by a dense cellular population and distributes made of mature plasma cells. Immunohistochemical study showed that only cells expressing the kappa light chain. IT is also noted for amyloid deposits. And the diagnosis was nasopharyngeal a location of a light chain Kappa to plasmacytoma with amyloid deposits (Figure 1,2 and 3).

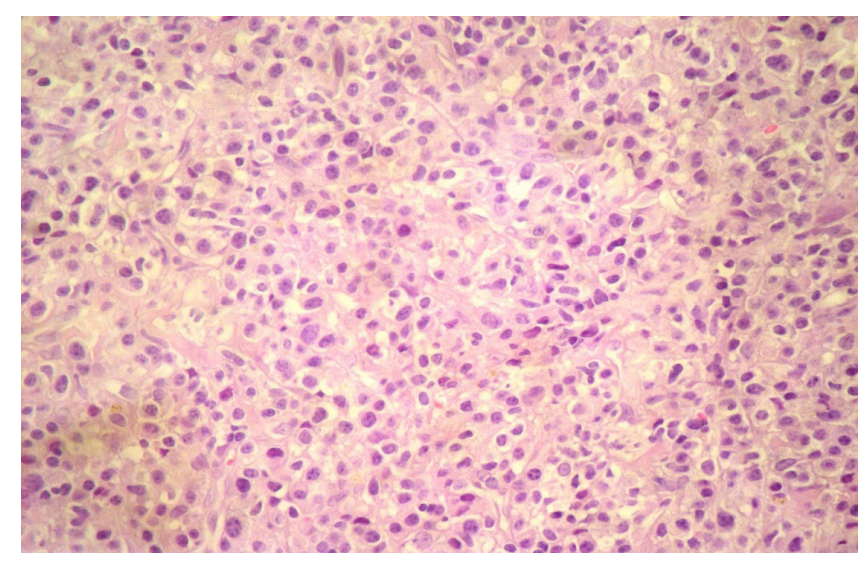

Figure 1: Marshall type of mature plasma cells (H.E X400) 


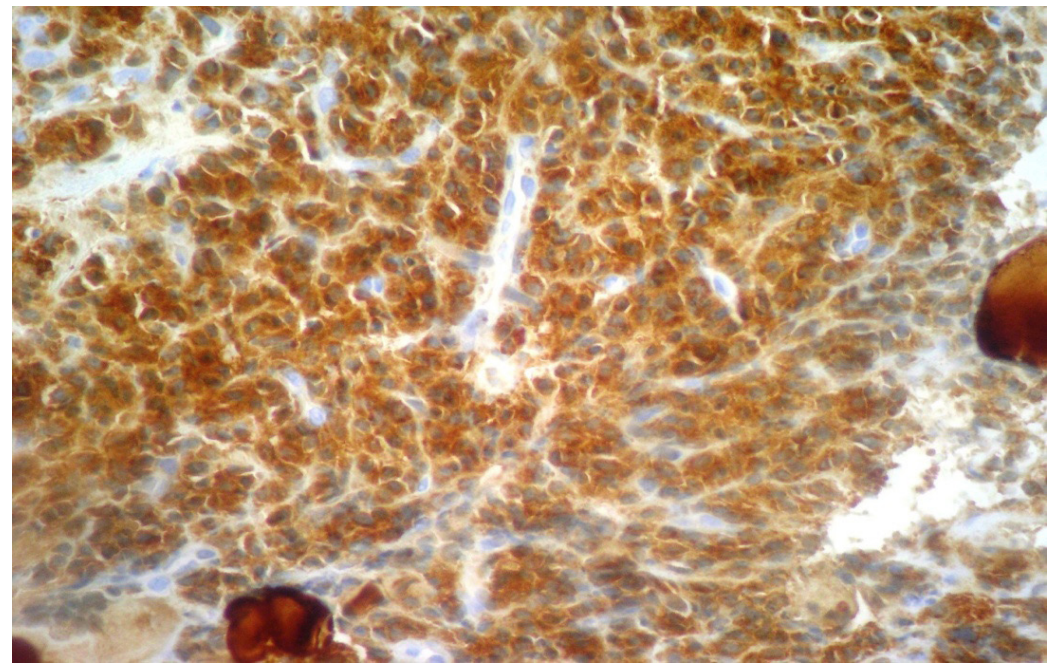

Figure 2: Exclusive expression of light chain Kappa (Immunohistochemistry)

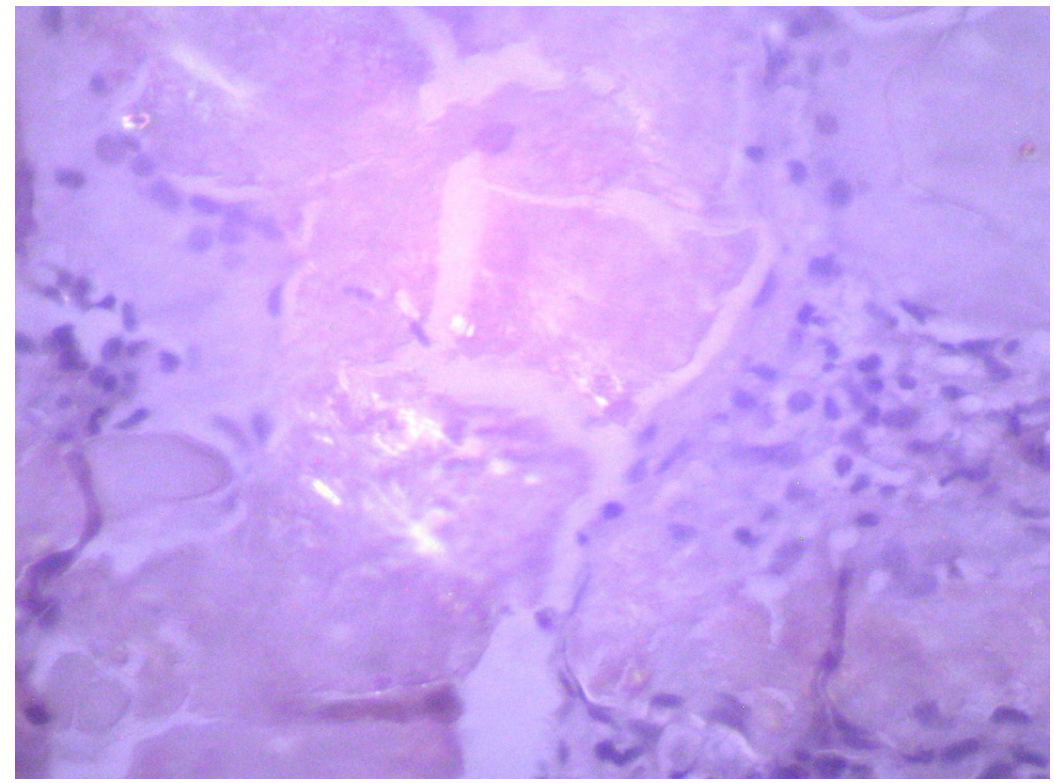

Figure 3: Deposits birefringent amyloid (Congo red and polarized light)

\section{Discussion}

The extramedullary plasmacytoma is rare with an average incidence of 3 per 100,000 inhabitants per year. This disease occurs in people above 40 years of age (over $95 \%$ of cases) affects 3 to 4 times more men than women. The clinical symptoms are more related to the specific location of the injury than to the nature of the tumor. In a series of 20 patients with extramedullary plasmacytoma of the head and neck, Kapadia and colleagues observed the following major symptoms: nasal obstruction in 35\%, epistaxis in 35\% (the two major symptoms of our patient), localized pain in $20 \%$, proptosis in $15 \%$, rhinorrhea in $10 \%$, regional lymphadenopathy in $10 \%$, and paralysis of the VI cranial nerve in $5 \%$ of cases.

The histological diagnosis is by objectifying a dense and diffuse tumor proliferation of mature plasma cells and plasma cell with prointranuclear inclusion Immunohistochemistry confirms monoclonality proliferation in objectification an exclusive expression of either kappa or lambda light chains $[1,3]$. The differential diagnosis is with other blooms round cell tumor: lymphoma, melanoma, neuroblastoma, and undifferentiated carcinoma. These diagnostics are easily removed by the use of immunohistochemistry. Compared to bone plasmacytoma, the prognosis is more favorable with survival rate approaching $90 \%$ five years. Some authors extramedullary forms would only be early manifestations of multiple myeloma and belong to the family of plasma cell dyscrasias. For other authors, forms extramedullary constitute a entity in its own right as evidenced by the spread to the territory of lymphatic drainage [1-4].

Regarding the treatment of extramedullary plasmacytoma in the head and neck, the choice of radiotherapy or surgery alone is controversial in the published data. Some authors advocate the use of radiotherapy as a sole treatment due to the good response in most cases. In 1993, Wax recommended surgery in cases of localized lesions that could be removed with minimal morbidity [3]. 
Radiotherapy and surgery can be combined, and this approach is used mainly when a tumor remains (no tumor remained in our case which explained why surgery wasn't recommended) [3].

Shah et al. recommend that the patient be monitored 28 and 36 months after primary treatment [5].

The patient received chemotherapy and radiotherapy with favorable evolution. The patient in the study completed 30 months of follow-up without reporting complaints regarding tumor recurrence.

\section{Conclusion}

The extramedullary plasmacytoma is a rare plasma cell proliferation malignant clone secreting a monoclonal immunoglobulin. Histological techniques are reported to be highly contributive in extramedullary plasmacytoma.

It is important for the otolaryngologist to acquire knowledge of this disease since 80 to $90 \%$ of the extramedullary plasmacytoma cases are found in the head and neck [6].

The possibility of a long-term transformation myeloma justifies the implementation of a comprehensive initial assessment and regular monitoring.

\section{References}

1. Bachar G, Goldstein D, Brown D, Tsang R, Lockwood G, et al. (2008) Solitary extramedullary plasmacytoma of the head and neck--long-term outcome analysis of 68 cases. Head Neck 30: 1012-9.

2. Clamp JR (1967) Some aspects of the first recorded case of multiple myeloma. Lancet 2: 1354-6.

3. Wax MK, Yun KJ, Omar RA (1993) Extramedullary plasmacytomas of the head and neck. Otolaryngol-Head and Neck Surg 109: 877-85.

4. Alexiou C, Kau RJ, Dietzfelbinger H, Kremer M, Spiess JC, et al. (2000) Extramedullary plasmacytoma; tumour occurrence and therapeutic concepts. Cancer 85: 2305-14.

5. Shah C, Roy D, Naronha B (2001) Extramedullary plasmacytoma of the submandibular gland. J Laryngol Otol 115: 1023-5.

6. Kuppersmith RB (1996) Extramedullary plasmocytoma of the head and neck.



